\title{
Parallels in reactionary argumentation in the US congressional debates on the abolition of slavery and the Kyoto Protocol
}

\author{
Marc D. Davidson
}

Received: 17 October 2005 / Accepted: 23 February 2007 / Published online: 27 April 2007

(C) Springer Science + Business Media B.V. 2007

\begin{abstract}
Today, the United States is as dependent on fossil fuels for its patterns of consumption and production as its South was on slavery in the mid-nineteenth century. That US congressmen tend to rationalise fossil fuel use despite climate risks to future generations just as Southern congressmen rationalised slavery despite ideals of equality is perhaps unsurprising, then. This article explores similarities between the rationalisation of slavery in the abolition debates and the rationalisation of ongoing emissions of greenhouse gases in the US congressional debates on the Kyoto Protocol.
\end{abstract}

\section{Introduction}

On July 4th, 1776, the 13 United States of America unanimously declared to "hold these truths to be self-evident, that all men are created equal, that they are endowed by their Creator with certain unalienable Rights, that among these are Life, Liberty and the pursuit of Happiness." Despite these 'self-evident truths,' slavery was upheld in many states and rationalised in congressional debates for almost another century before it was formally abolished by the US Congress in 1865 (see e.g. Jenkins 1935; Tise 1987; Miller 1996). On June 12th, 1992, the United States signed the United Nations Framework Convention on Climate Change (UNFCCC), in which the Parties stated their determination "to protect the climate system for present and future generations." Despite this commitment, the US Congress has as yet rejected any mandatory regulation of greenhouse gases, including the binding emission targets for the industrialised nations agreed to under the Kyoto Protocol (see e.g. PEW Center on Global Climate Change 2004).

This article explores similarities between the rationalisation of slavery by congressmen from the Southern United States in the abolition debates in the mid-nineteenth century and the rationalisation of ongoing greenhouse gas emissions in the congressional debates on the Kyoto Protocol (see also Orr 2000). In the main, I leave the quotations to speak for themselves. I do not claim that all or even a majority of US congressmen and women

M. D. Davidson $(\bowtie)$

Department of Philosophy, Faculty of Humanities, University of Amsterdam,

Nieuwe Doelenstraat 15, 1012 CP Amsterdam, The Netherlands

e-mail: m.d.davidson@uva.nl 
approve of all the arguments quoted, which - even if it were so - would be impossible to prove. ${ }^{1}$ However, anyone taking the time to read through the congressional records will see that the quotations do not give a twisted view of the general sentiments expressed in the US Congress in the case of the Kyoto debate (see also Müller 2000) and by Southern congressmen in the case of the abolition debate. Most quotes can easily be retraced from the Register of Debates in Congress (RDC) the Congressional Globe (CG), and the Congressional Record (CR), all available at the Internet.

This article is structured as follows. In Section 2 I describe the similarities between the circumstances under which the abolition debate and 'Kyoto' debate were and are being conducted. In Section 3 I show that several types of argument against social change are found to recur in the US congressional debates on both issues. As this particular comparison runs the risk of being labelled demagogic, I shall also argue that the arguments cited from the climate debate are suspect in their own right. In Section 4 some conclusions are drawn.

\section{Similarities between slavery and the use of fossil fuels}

In this section I argue that the present climate debate shows several fundamental similarities in circumstance with the abolition debate of the mid-nineteenth century. In both debates US congressmen and Southern congressmen, respectively, represent an electorate with substantial interests in maintaining the status quo (Section 2.1), costs are shifted to people who are not part of the electorate (Section 2.2), and Congress rejects proposals for change (Section 2.3).

\subsection{Vested interests of the electorate}

Both the abolition and the climate debate revolve around 'energy resources' considered vital to the economy and pivotal to everyday life. In the mid-nineteenth century slave labour was the cheap and indispensable energy source underpinning the economies of the Southern United States. While the Northern States industrialized, the chief economic sectors in the South, such as cotton cultivation and production of other crops, were entirely dependent on slavery. In 1860 there were about four million slaves of African descent in a total Southern population of 12 million (U.S. Census 1860). Not all southerners had an equal interest in the institution of slavery. Only one in every four southerners owned slaves, and non-slave owners also had to contribute to the costs of upholding the institution of slavery. Some of the free labourers were forced into lower-paid jobs than might have been available in the absence of slavery. Nevertheless, much of the economy was tied to this free labour source, be it directly or indirectly. The slavery-centred economic system offered white non-slave owners jobs at plantations, in the trading sector in products bought from or sold to plantations, and in support sectors such as shipbuilding, banking, and insurance. Consequently, many Southerners could not imagine their prosperous society existing without the institution of slavery, as expressed by Governor Hammond on the senate floor on March 4, 1858 (CG, p. 962):

"In all social systems there must be a class to do the mean duties, to perform the drudgery of life. That is, a class requiring but a low order of intellect and but little

\footnotetext{
${ }^{1}$ This article focuses on the congressional debates on the Kyoto Protocol. I do not deny that some individual states or businesses are taking a more pro-active position (PEW 2004). Neither do I deny that former US president Clinton and vice-president Gore have been far ahead of congress as well.
} 
skill. Its requisites are vigor, docility, fidelity. Such a class you must have or you would not have that other class which leads progress, civilization, and refinement. It constitutes the very mud-sills of society and of political government; and you might as well attempt to build a house in the air, as to build either the one or the other, except on the mud-sills. Fortunately for the South, she has found a race adapted to that purpose to her hand ... We use them for the purpose and call them slaves."

Nowadays, the use of fossil fuels, an energy source applied to replace human labour, is closely woven into almost every facet of modern production and consumption. The 'oil crisis' of the seventies and eighties clearly demonstrated this dependence on fossil fuels. With its $4.6 \%$ of global population the United States is responsible for one-quarter of global oil consumption (EIA 2004). Reducing the risks of climate change may demand substantial reductions in combustion of fossil fuels, however, implying substantial changes in longcherished ways of life and consumption patterns. There is no cheap 'technological fix,' as there has been for many other environmental problems. As Senator Craig expressed this dependence on energy on the senate floor on April 20, 1998 (CR, S3245):

"So let me say to all Senators and to the American people, tonight, walk around your house. Think about the light fixture you have just turned on, the appliance you have just turned off, the telephone device you might make a call on, or the computer you will sit down to, to communicate anywhere in the world. Many of these things you have added to your home since 1990. Look at the car you drove home from work. And to the farmer who is out there on the plains and the farmlands of America this very hour, that marvelously efficient diesel tractor that is pulling the plow and the drill to plant the crop that creates the abundant harvest that feeds not just the people of America but the people of the world. All of those tools are a product of energy. In fact, Americans today are consuming more energy as the economy continues to grow, and we will need to consume more. We will need to turn on our lights and our computers. We will need our cars. In the future, they will be better and they will be cleaner, but they still must consume energy."

Obviously, US congressmen represent a wide variety of interests. The interests of an oil company in the status quo are different from those of a software producer, and rising energy prices will hit energy-conscious consumers less hard than owners of sport utility vehicles. US congressmen may well be more susceptible to certain interests than others. While the scope and influence of these various interests may differ, though, virtually the whole electorate uses fossil fuels in one way or the other. Apart from specific groups like manufacturers of solar cells or windmills, few people have a personal interest in rising energy prices. Although economic forecasts vary widely, there are few studies predicting that climate policy will benefit employment or economic growth (see e.g. EIA 1998; Azar and Schneider 2002).

\subsection{Transfer of costs to third parties}

In both the slavery and fossil fuel and climate debate, the electorate shifts costs to people that are not part of the electorate. In the case of slavery, the shifting of costs to the slaves themselves requires no further explanation. Moreover, the Southern United States shifted costs to the Northern States. Although the Northern States had already abolished slavery, the enforcement costs of upholding the institution of slavery were spread over the federation, for example by the Fugitive Slave Act of 1850 (Hummel 1996). 
In the case of fossil fuel use the issue is more complex but hardly less of a moral issue than was slavery two centuries ago. The report Climate Change 2001: Impacts, Adaptation and Vulnerability, by IPCC Working Group II, assesses the sensitivity, adaptive capacity and vulnerability of natural and human systems to climate change and the potential consequences of that change. Among the findings to emerge are that "natural systems are vulnerable to climate change, and some will be irreversibly damaged" and that "many human systems are sensitive to climate change and some are vulnerable." Potentially serious impacts of climate change include sea level rise; changes in agriculture, forests and fisheries; changes in the energy, water, construction, transport and tourism sectors; increased risk of disaster: changes in the frequency and severity of storms, floods, droughts, hurricanes and precipitation levels; changes in biodiversity; increased human morbidity and premature mortality; and human migration.

What makes climate change pre-eminently a moral issue is that due to the inertia of the climatic system the bulk of impacts of climate change will clearly not be felt for another 50 years or more, when future generations will occupy this planet rather than present generations (Hansen 2005). In other words those creating the risks are not the same as those bearing them. With a few negligible exceptions, mitigation measures would therefore cost present generations more than they would benefit in the form of risk reduction. Or, in economic terms, few mitigation measures would survive an egocentric cost-benefit analysis by the present electorate. Future generations, by definition, have no direct say in presentday decision-making; they are not part of the present electorate. It is present generations that decide whether or not to improve the living conditions of future generations by mitigating climate change.

Apart from this intergenerational shifting of costs, there is also intra-generational shifting, for each country holds that the benefits of fossil fuel use are reaped domestically, while the costs of climate change are diffused across the world. Although in principle the 'import' of climate costs might balance the 'export,' in practice it does not. As mentioned, in 2001 the United States emitted about $24 \%$ of global energy-related carbon dioxide emissions (EIA 2004), while its population and land surface amounted to $4.6 \%$ (US Census Bureau 2004) and 6.4\%, respectively.

\subsection{Resistance to social change}

In the case of both slavery and fossil fuel use, there is and was widespread resistance to social change, unsurprisingly in the light of the cited vested interests at stake. It existed when slavery was abolished - in the United States sufficient to start a civil war - and it exists today with respect to cutting consumption of fossil fuels. Although the risks of climate change have been on the political agenda for decades - in 1988 then-NASA scientist James Hansen testified before Congress that global warming "is already happening now" - it took until 1992 before the global community acknowledged the problem and agreed on establishing the UNFCCC for future action. It took five more years before the general agenda of the UNFCCC was translated into binding targets for the industrialised world for the coming years. In 1997, in Kyoto, a protocol was formulated which asks the industrialised countries to reduce their greenhouse gas emissions by at least 5\% below 1990 levels in the commitment period 2008-2012. The Kyoto Protocol entered into force and became legally binding on February 16th, 2005, following ratification by Russia at the end of 2004. Right from the start, however, the US Senate rejected the Kyoto Protocol, unanimously adopting the so-called Byrd-Hagel resolution in 1997 (CR, S5622), a position embraced by the White House in 2001 (Bush 2001). Since then, no alternative international framework for the Kyoto Protocol has been proposed. 
Since the 1997 debates on the Kyoto Protocol, there has been an increase in the number of climate change-related legislative proposals introduced in the US Congress. To date, however, not a single item of legislation has been enacted to curb greenhouse gas emissions (PEW Center on Global Climate Change 2004). On February 14, 2002, US President Bush announced a new climate change strategy for the United States. However, the strategy involved a voluntary domestic "greenhouse gas intensity" target that would allow US emissions to actually increase by $12 \%$ by 2012 , and established no mechanism for ensuring that even that target will be met (PEW Center on Global Climate Change 2004). On August 28, 2003, the US government's Environmental Protection Agency declared that carbon dioxide and other greenhouse gasses are not air pollutants under the Clean Air Act and therefore cannot be regulated under the Clean Air Act (EPA 2003). In October 2003, the Senate voted for the first time on a measure to limit US economy-wide greenhouse gas emissions, the Climate Stewardship Act (S.139) introduced by Senators Joseph I. Lieberman and John McCain. The measure did not pass, however. Amendments to the Energy Policy Act requiring automotive fuel efficiency standards were similarly defeated by the House and Senate.

\section{Reactionary rhetoric}

In Arguing About Slavery, Miller (1996, p. 11) does not draw any parallels between slavery and fossil fuel use, but points in the direction of what might be found were one to do so:

"Suppose today some dominant industry, built into the lives and fortunes of a great many people - to a degree of the whole nation - were found to be morally repugnant; what difficulties there would then be in extracting it from the nation's life!...Slavery was integral to the life and culture, as John C. Calhoun kept saying, of an entire region, of eleven states (in 1835) of the Union - of almost half of the nation. When a "pecuniary interest" has that magnitude, it is a formidable opponent indeed. Rationalizations are supplied, positions are softened, conflicts are avoided, compromises are sought, careers are protected, life goes on. Don't try to change what can't be changed. Adapt to it."

In the previous sections, I have argued that fossil fuel use is indeed as "integral to the life and culture" of the United States today as slavery was for the Southern United States in the mid-nineteenth century. That US congressmen tend to rationalise ongoing fossil fuel use despite climate risks to future generations just as Southern congressmen rationalised slavery despite ideals of equality is perhaps not surprising, therefore. ${ }^{2}$ In the following subsections,

\footnotetext{
${ }^{2}$ For other discussions of reactionary rhetoric see, for example, Albert Hirschman's (1991) The Rhetoric of Reaction. Hirschman argues that for (at least) the past 200 years reactionary thinkers have argued against progressive agendas and reforms through a recurrent pattern of polemical postures and manoeuvres built up around three main theses. First, the Perversity Thesis: "any purposive action to improve some feature of the political, social, or economic order only serves to exacerbate the condition one wishes to remedy." Second, the Futility Thesis: "attempts at social transformation will be unavailing, that they will simply fail to "make a dent." Third, the Jeopardy Thesis: "the cost of the proposed change or reform is too high, as it endangers some previous, precious accomplishment." Hirschman draws his examples from three historic epochs: the French Revolution and the rise of individual liberties, universal suffrage and the rise of democracy in the nineteenth century, and the rise of the welfare state in the twentieth century.
} 
I discuss six specific arguments cited in the US Congress against the abolition of slavery that are now being voiced against ratification of the Kyoto Protocol, elucidating briefly why they are rhetorically suspect.

\subsection{What is deemed bad is in fact good}

The most direct argument against social change is a complete reversal of claims: what the advocates of change call bad is in fact a positive good. In public discourse about the abolition of slavery it was argued that slaves would be better off and socially securer than free people in Africa or the poor in the Northern States of the US. Abolition of slavery would therefore worsen the position of slaves rather than improve it, as senator en vicepresident John Caldwell Calhoun argued on the senate floor on February 6, 1837 (RDC, p. 718-9):

"the Central African race...had never existed in so comfortable, so respectable, or so civilized a condition as that which it now enjoyed in the Southern States"...Slavery was not "an evil. Not at all. It was a good - a great good."

Thomas R. Dew, professor and later president of William and Mary College, gave similar arguments in his Review of the Debate in the Virginia Legislature of 1831 and 1832 (Simms 1852):

"“"There is a time for all things," and nothing in this world should be done before its time. An emancipation of our slaves would check at once that progress of improvement which is now so manifest among them" (p. 443).

"A merrier being does not exist on the face of this globe, than the negro slave of the U. States” (p. 459).

In the congressional debates about the Kyoto Protocol the claim that global warming would be harmful has similarly been completely reversed, it being held that increases in global levels of greenhouse gases and temperature would actually be beneficial. Senator Inhofe, chairman of the Environment and Public Works Committee, for example, took this position on the senate floor on July 28, 2003:

"Thus far, no one has seriously demonstrated any scientific proof that increased global temperatures would lead to the catastrophic predictions by alarmists. In fact, it appears just the opposite is true, that increases in global temperature have beneficial effect on how we live our lives. (CR, S10013)... What gets obscured in the global warming debate is the fact that carbon dioxide is not a pollutant. It is necessary for life. Numerous studies have shown that global warming can actually be beneficial to mankind." (CR, S10019)... it would be beneficial to our environment and the economy." (CR, S10022).

What makes these arguments suspect is that by "numerous studies" Inhofe does not refer to the assessment of peer-reviewed literature by the International Panel on Climate Change, established by the World Meteorological Organization and the United Nations Environment Programme, but to a specific review by Robinson et al. (1998) that was neither peerreviewed nor published in a scientific journal. The Oregon Institute of Science and Medicine used the manuscript, made up in a nearly identical format to scientific articles published in the Proceedings of the National Academy of Sciences, to persuade 17,000 people with an academic degree to sign the so-called Oregon Petition opposing the Kyoto 
Protocol (see http://www.oism.org/pproject/index.htm). The Council of the National Academy of Sciences, however, issued a statement that neither the petition nor the accompanying manuscript had anything to do with them and that they disagreed with its conclusions and recommendations (NAS 1998).

\subsection{The benefits of the proposed policy are uncertain}

A second kind of argument against social change, more subtle and heard more often than a direct reversal of claims, is the idea that we are simply too ignorant about the future benefits of change. This might seem a particularly modern argument, especially suitable for the climate debate. However, William Harper, chancellor and senator of South Carolina, argued in 1838 in his Memoir on Slavery that we are ignorant as to whether abolition of slavery would in fact benefit the slaves themselves:

"And I would impress most earnestly, that with our imperfect and limited faculties, and short-sighted as we are to the future, we can rarely, very rarely indeed, be justified in producing considerable present evil or suffering, in the expectation of remote future good - if indeed this can ever be justified." (in: Simms 1852, p. 18).

"Very different indeed is the course of [the abolitionists] whose precipitate and ignorant zeal would overturn the fundamental institutions of society, uproar its peace and endanger its security, in pursuit of a distant and shadowy good, of which they themselves have formed no definite conception - whose atrocious philosophy would sacrifice a generation - and more than one generation - for any hypothesis." (in: Simms 1852, p. 98).

Uncertainty about the benefits of change is a popular argument against the Kyoto Protocol as well. Many US senators have argued that there is no 'proof' or scientific consensus about global warming, despite growing indications that human activity is indeed largely responsible for global climate change. While the IPCC concluded in its Second Assessment Report (1995) that "The balance of evidence suggests a discernible human influence on global climate," many senators doubted the IPCC's conclusions, such as senator Hagel on the house floor on October 3, 1997:

"Mr. President, the fact is this treaty is not based on sound science. The scientific community has not definitely - even close to definitely - concluded that there is global warming caused by human actions. The science is inconclusive and often contradictory" (CR, S10309).

In its Third Assessment Report the IPCC (2001) reinforced its previous claim: "There is new and stronger evidence that most of the warming observed over the last 50 years is attributable to human activities." In 2001 the U.S. National Academy of Sciences confirmed the IPCC's major conclusions, after being requested by the White House to review the findings of that body: "The changes observed over the last several decades are likely mostly due to human activities, but we cannot rule out that some significant part of these changes is also a reflection of natural variability" (NAS 2001). The new IPCC and NAS findings did not move the senators, however, as expressed for example by representative Rohrabacher on the house floor on June 12, 2001:

"The National Academy of Science report is filled with weasel words and caveats. That was true of many of the other scientific investigations. Almost every one of the 
scientific investigations, the findings about global warming were not conclusive enough to make any solid statement other than words to the effect that further research is necessary." (CR, H3053).

As recently as July 28, 2003, Senator Inhofe, chairman of the Environment and Public Works Committee, stated on the senate floor that:

"After studying the issue over the last several years, I believe the balance of the evidence offers strong proof that natural variability, not manmade, is the overwhelming factor influencing climate, and that manmade gases are virtually irrelevant." (CR, S10013).

How to take account of controversial information is a difficult matter, of course. To make a decision we must first weigh up the judgments of the various 'experts' on the basis of their credibility as well as our own attitude towards risk. If we are generally 'rather safe than sorry,' we will attach more importance to information that is unpleasant rather than reassuring. If we are risk seeking, on the other hand, we will attach rather less weight to unpleasant information. In the context of everyday risk management, however, the demand for 'definite conclusions' and lack of controversy before action is taken, as required by the US Congress when it comes to cutting fossil fuel consumption, is uncommon practice and in fact unprecedented. Policy-makers frequently take serious, far-reaching decisions on the basis of information generated by (economic) models that are far less reliable than the models used in climate science. No one seems to advocate inaction because of the uncertainties involved in these economic projections. For example, it is unlikely that any of the economic models used by the US government to predict economic growth and future employment would survive scrutiny as thorough as that to which climate models are subjected by the IPCC and all the additional questioning involved in public debate. Secondly, the bias of US Congressmen towards scientific information about climate change clearly shows up when compared to their attitude towards the perceived threat of Saddam Hussein possessing weapons of mass destruction. For example, the same senator Inhofe who insisted upon 'sound science,' consensus among scientists and complete scientific certainty before devoting funds to climate mitigation, found sufficient justification in inconclusive information from the US intelligence service, contradicting the conclusions of the chief UN weapons inspector, to start a war on Iraq (see e.g. CNN Late Edition, August 25, 2002). In short, although there is no uniquely 'right' approach to risk assessment, consistency is a prime consideration in any intellectual debate.

\subsection{Change brings economic ruin}

Perhaps the most important argument against social change is that it would have devastating economic effects. Much use was made of this argument in the abolition debate, for example by James Henry Hammond, senator and later governor of South Carolina on the House floor on February 1, 1836 (RDC, p. 2456):

"There are about 2,300,000 slaves at this moment in the United States, and their annual increase is about 60,000. Sir, even the British Government did not dare to emancipate its enslaved West India subjects without some compensation. They gave them [the owners] about sixty percent of their value. It could scarcely be expected that this Government would undertake to free our slaves without paying for them. Their value, at $\$ 400$, average, (and they are now worth more than that,) would amount to 
upwards of nine hundred millions. The value of their annual increase, alone is twentyfour millions of dollars; so that to free them in one hundred years, without the expense of taking them from the country, would require an annual appropriation of between thirty-three and thirty-four millions of dollars. The thing is physically impossible."

A second example can be found in Dew's Review of the Debate in the Virginia Legislature of 1831 and 1832 (Simms 1852, p. 384):

"There is slave property of the value of $\$ 100.000 .000$ in the State of Virginia, \&c., and it matters but little how you destroy it, whether by the slow process of the cautious practitioner, or with the frightful dispatch of the self-confident quack; when it is gone, no matter how, the deed will be done, and Virginia will be a desert."

In the climate debate it is likewise argued that the Kyoto Protocol would be 'devastating' for the US economy, as illustrated by the following three quotations:

"The economic impact would be devastating for the United States. We would see the loss of millions of jobs, entire industries would flee to other countries, our people would face higher fuel costs, higher taxes, leading to lower productivity and a lower standard of living. ... And it would have a devastating impact on our national security interests. ... One of the biggest users of fossil fuels in America is what? The U.S. military" (Senator Hagel, October 3, 1997, CR, S10309-10310).

"Every credible economic study on this treaty paints a dark picture for the American people. According to the Wharton Econometric Forecasting Associates (WEFA), the Kyoto treaty would cause energy prices to soar and the standard of living in our country to plummet. In a well-respected study, WEFA found that the Kyoto treaty would result in the elimination of over 2.4 million American jobs by the year 2010 and cost the average American family over \$2.700 a year" (Representative Knollenberg, May 20, 1999, at the hearing "Kyoto Protocol: Is the Clinton-Gore Administration Selling Out Americans?", subcommittee on National Economic Growth, Natural Resources, and Regulatory Affairs).

"The most widely cited and definitive study came from Wharton Econometric Forecasting Associates. According to Wharton Econometric Forecasting Associates' economists, Kyoto would cost 2.4 million U.S. jobs and reduce GDP by 3.2 percent, or about $\$ 300$ billion annually, an amount greater than the total expenditure on primary and secondary education in America" (CR, S10014).

"Kyoto is an economic weapon designed to undermine the global competitiveness and economic superiority of the United States" (Senator Inhofe, July 28, 2003, CR, S10021).

Although the substantial costs involved in implementing the Kyoto Protocol cannot be ignored, in the case of the climate debate there are reasons to distrust these particular economic arguments. First, it should be noted that the study Global Warming: The High Cost of the Kyoto Protocol by Wharton Econometric Forecasting Associates (WEFA 1998), which has been the study most widely cited in congressional debates and considered definitive, was in fact commissioned by the American Petroleum Industry. The study ignored many of the options available under the Kyoto Protocol that would lower the costs of compliance, such as reducing emissions of non- $\mathrm{CO}_{2}$ greenhouse gases, the use of 'sinks' and emission trading or the Clean Development Mechanism (the so-called flexible mechanisms of the Kyoto Protocol). A review study by the Energy Information Administration, 
an independent statistical and analytical agency of the US Department of Energy, showed that other studies - also available to members of Congress - arrived at much lower estimates of economic impact than the WEFA study (EIA 1998). A second reason for suspicion is the inconsistent approach to scientific information: while the darkest available picture of the economic cost of climate policy is readily taken for granted, equally dark pictures of climate change are ignored entirely.

A third point is that much of the impression made by a macro-economic study depends on how results are presented. When quoted as sum-total costs, the billions of US dollars cited in such studies create an impression that the cost of $\mathrm{CO}_{2}$ reductions is so great as to threaten economic development. However, if one remembers that income is forecast to grow consistently by several percent a year, the cost of climate policy "amounts to 'only' a couple of years delay in achieving very impressive growth in per capita income levels" (Azar and Schneider 2002). One and a half centuries ago, Abraham Lincoln (1860) used a story to illustrate how the pecuniary interests of the slave owners expressed in large macroeconomic terms influenced their (moral) judgment (see Tise 1987). There was, said Lincoln, an argument between two pastors. One pointed to a word in the Bible. "Do you see that word?" "Yes, of course." Then the first pastor put a gold coin over the word. "Do you see it now?" The audience laughed. "Whether the owners of this species of property [slaves] do really see it as it is," Lincoln went on, "it is not for me to say, but if they do, they see it as it is through 2,000,000,000 of dollars, and that is a pretty thick coating." The audience laughed. "Certain it is," Lincoln continued, "that they do not see it as we see it. Certain it is, that this 2,000 million of dollars, invested in this species of property, all so concentrated that the mind can grasp it at once - this immense pecuniary interest, has its influence upon their minds."

\subsection{Solo action will be ineffective and unfair}

Social change is seldom set into motion simultaneously around the world, which means different rules may hold in different regions. This provides a seemingly rewarding argument against social change: solo action would be unfair and ineffective. The abolition of slavery in the Southern States, for example, would lead to inequality and compulsion among slaveholders elsewhere, as argued by Dew (Simms 1852, p. 382):

"Every prudent slaveholder in the slaveholding part of the State, would either migrate with his slaves to some State where his rights in slave property would be secured to him by the laws, or would surrender at once his rights in the parent stock as well as in their future increase, and seek some land where he may enjoy at least the earnings of his own industry."

In the case of the congressional debates on the Kyoto Protocol, the US senate rejected the protocol because it would not require developing countries to reduce their emissions, too, and would thus be ineffective and unfair. The Byrd-Hagel resolution (CR, S5622), passed in the US Senate in 1997 by a 95-0 majority, states that the US "should not be a signatory to any protocol...unless the protocol or other agreement also mandates new specific scheduled commitments to limit or reduce greenhouse gas emissions for Developing Country Parties within the same compliance period." In March 2001, President George W. Bush confirmed his support to the Byrd-Hagel resolution in a letter to the Senate describing as "unfair" the exemption of countries like India (Bush 2001) and calling the Kyoto Protocol 'ineffective.' The unanimity of the US Senate is explicit enough, but 
several quotes may serve to exemplify the sentiments expressed. Let me first turn to the alleged ineffectiveness of the Kyoto Protocol:

"We won't even get reduced carbon emissions. That's because every ton of reduced emissions in the United States and other developed nations will be made up - and then some - in the developing world" (Senator Ford, June 12, 1997, CR, S5625).

"Even from an environmental standpoint, the Kyoto Protocol is a failure. ... Even if one accepts the validity of the science on global warming, which is still uncertain and at best contradictory, this treaty would do nothing to stop any of these emissions" (Senator Hagel, April 20, 1998, CR, S3241).

“... the global warming treaty will create more pollution, not less, because it exempts the countries that permit the dirtiest of industrialization" (Representative Rohrabacher, July 27, 2001, CR, H4774).

Whether the Kyoto Protocol is effective depends entirely on how it is implemented, though. If it merely sets restrictions on industries competing on the international market, the protocol would indeed accomplish little, for industries could just move to developing countries. However, not all industry is exposed to international competition and, more importantly, climate policy can also be designed to address domestic consumption. There is no reason to assume that the emission reductions to be achieved in the developed world by increasing fuel prices for domestic use such as private transport would be cancelled by greater fuel use in developing nations. Neither would tighter regulations on insulation of buildings result in increased emissions by developing countries, to name just some of the possibilities.

Apart from being 'ineffective,' the Kyoto Protocol has also been characterised as "blatantly unfair" (Senator Murkowski, April 20, 1998, CR, S3242), or in the following words:

"I have a long record of defending the American worker and American industry from unfair business and trade practices overseas - many of which occur in these developing countries. My fear is that failing to include developing nations in this agreement will undermine America's ability to compete internationally and will only work to force American industry overseas to these developing areas." (Senator Hollings, CR, S5887, June 17, 1997).

"The treaty is also patently unfair because it exempts 77 percent of all countries from any obligations. China, India, Mexico, and Brazil, just to name a few, are completely unfettered by the Treaty - these countries already have the competitive advantages of cheap labor, lower production costs, and lower environmental, health, and safety standards. If President Clinton has his way, now these countries will be free to develop and pollute all they want, while the U.S. economy goes into a deep freeze." (Senator McIntosh, May 20, 1998).

What makes the US Senate's rejection of the Kyoto Protocol on the basis of its 'unfairness' suspect is, first, the fact that the greenhouse emissions of the average North American outstrip those of the average citizen of India, say, by a factor 20. This inequality was taken into consideration under the UNFCCC, which the United States signed in 1992. In the UNFCCC it was noted "that the largest share of historical and current global emissions of greenhouse gases has originated in developed countries, that per capita emissions in developing countries are still relatively low and that the share of global 
emissions originating in developing countries will grow to meet their social and development needs...." On the basis of these considerations and others, Article 3, Principle 1 of the UNFCCC states that: "the developed country Parties should take the lead in combating climate change and the adverse effects thereof." As a direct result of this article, developing countries are not subject to binding emissions targets under the Kyoto Protocol.

Many developing countries, such as India, China and the African countries, have proposed commitments to which they could agree and which would ensure a 'level playing field' for internationally competing industries. One such proposal is to allocate (tradable) emission rights to countries on a per capita basis (see e.g. Müller (2001) and Meyer (2000) for a proposal including convergence from 'grandfathering' to per capita allocation). This would indeed level the playing field, as emitting greenhouse gases would then cost the same throughout the world. However, because of the higher per-capita emissions in the developed countries like the US, such a scheme would result in substantial financial flows from the developed to the developing world. During the Kyoto Protocol negotiations of 1997, the delegation of Brazil made an even more far-reaching proposal: to distribute the burden of emission reductions among Parties proportional to their relative share of responsibility for climate change. Such a scheme would also take historical emissions into account and would therefore result in even fewer emission rights for developed countries than under the equal per-capita scheme.

From the debates in the US Congress, however, emerges no willingness to embrace proposals that might lead to payments being made to developing countries. That means that congress' idea of 'fairness' does not primarily relate to the idea of an economic 'level playing field,' but to the idea of 'historical rights': if the global community decides on a ceiling for greenhouse gas emissions, past emissions imply acquired rights. In this view, the United States has legitimately 'settled' in a quarter of globally available - previously unoccupied - 'emission territory.' Why should Americans give way and incur costs while people in the developing countries do not?

While congress' view of international 'fairness' may or may not be sincerely felt, there are grounds for further suspicion. First, the 'unfairness' of an international agreement cannot in itself be sufficient reason for rejecting climate policy. For example, the fact that slavery is not abolished by other countries cannot serve as a reason for upholding it. Second, over the last few years the US has often acted unilaterally or used 'power play' to force other countries to accept the US position on global political issues. Examples include the war on Iraq and the International Criminal Court, where the US has forced other countries into agreements that no US citizen could ever be handed over to the court. Remarkably, the US does not use this kind of 'power play' in the climate negotiations. This passivity and inconsistency once more indicates that US Congress does not see global warming as a problem.

\subsection{Sovereignty}

In Arguing About Slavery, Miller (1996) shows that a central issue in the US congressional debates on slavery was the legitimacy of raising the subject at all at the congress or federal level. Many congressmen considered slavery a 'domestic institution' to be dealt with at the state level. Despite the Constitution guaranteeing citizens the right "to petition the government for a redress of grievances," on May 18, 1836, the House of Representatives adopted a 'gag rule' whereby all petitions relating to slavery would automatically be tabled without consideration. In his 1849 speech The Southern Address, senator and vice-president 
John C. Calhoun emphasised the element of sovereignty and individual freedom of choice (Calhoun 1849):

"Slavery is a domestic institution. It belongs to the States, each for itself to decide, whether it shall be established or not; and if it be established, whether it should be abolished or not. Such being the clear and unquestionable right of the States, it follows necessarily that it would be a flagrant act of aggression on a State, destructive of its rights, and subversive of its independence, for the Federal Government, or one or more States, or their people, to undertake to force on it the emancipation of its slaves....

It is not for them, nor for the Federal Government to determine, whether our domestic institution is good or bad; or whether it should be repressed or preserved. It belongs to us, and us only, to decide such questions."

Today, many US congressmen are equally horrified by the idea of supranational bodies having a say in domestic affairs such as US energy consumption, as exemplified in the following quotations:

"It cuts to the heart of our national sovereignty by setting up an international authority that would subject U.S. businesses and industries to its authority and penalties. Never before in the history of this free Nation has that occurred. This is one U.S. Senator that will not allow it to occur" (Senator Hagel, October 3, 1997, CR, S10310).

"Mr. President, I believe this will be the first time in the history of our country that a President has allowed foreign interests to control and to limit the growth of the American economy. ... Never before have we allowed foreign interests to dictate the amount of energy Americans can use" (Senator Craig, April 20, 1998, CR, S3245).

"I am not about to give up my freedom to a bunch of unelected officials from other countries. ... within 10 years all of these bodies will be run by corrupt Third World people who are probably going to be bribed by Communist China" (Representative Rohrabacher, July 27, 2001, CR, H4774).

As sincere as this fear of supranational bodies may be, however, the arguments become suspect if they are not accompanied by proposals for unilateral action. So far, the United States has not set any binding domestic targets for greenhouse gas emissions (PEW Center on Global Climate Change 2004).

\subsection{Social change will hit other groups}

Another argument against social change is that trying to benefit one vulnerable group might harm certain other vulnerable groups. The argument is popular, since it distracts attention from the interests in the status quo of the one who uses the argument. Thus, in the slavery debate it was argued that abolition would be at the expense of women, a point only deemed valid because true emancipation was not to be afforded to women, either. Take, for example, Dew arguing against abolition (Simms 1852, p.338-9):

"The labor of the slave thus becomes a substitute for that of the woman; ... She is now surrounded by her domestics, and the abundance of their labor lightens the toil and hardships of the whole family. She ceases to be a mere "beast of burthen;" ... [W]e behold the marked effects of slavery on the condition of women ... no longer the slave, but the equal and the idol of man." 
Of particular interest in the abolition debate was the argument that slavery was deemed necessary to ensure liberty and equality between the white, male part of the population, as expressed most clearly by an editor of the Richmond Enquirer (April 15, 1856):

"In this country alone does perfect equality of civil and social privilege exist among the white population, and it exists solely because we have black slaves,"..."Freedom is not possible without slavery."

Or take Representative (and future governor) Henry A. Wise from Virginia on the house floor on January 26, 1842 (CG, p. 173):

“...wherever black slavery existed, there was found at least an equality among the white population; but where it had no place, such equality was never to be found."..."The principle of slavery was a leveling principle; it was friendly to equality. Break down slavery, and you would with the same blow break down the great Democratic principle of equality among men."

In the case of the climate debate, Senator Craig argued on the house floor on April 20, 1998, that the Kyoto Protocol would be at the expense of the starving in poor countries:

"One of the potential tragedies of this treaty would be the higher cost of food, not just for those who can afford it but for those who cannot. And remember our JudeoChristian ethic as a country, the hundreds of millions of dollars of food we send around the world to poor nations, to starving people. Could we afford to send more if it cost more? I doubt it" (S3245).

Similarly, according to Senator Inhofe (July 28, 2003), the Kyoto Protocol would be at the expense of poor minorities in the US:

"[The Kyoto Protocol] affects the poverty rates for Blacks and Hispanics. ... it is discriminatory against these particular individuals. ... Kyoto will cost 511,000 jobs held by Hispanic workers and 864,000 jobs held by Black workers. Poverty rates for minority families will increase dramatically, and because Kyoto will bring about higher energy prices, many minority businesses will be lost. ... Kyoto and Kyoto-like policies developed in this body would cause the greatest harm to the very poorest of Americans" (S10015).

However, the interests of people vulnerable to climate change need not necessarily compete with those of other vulnerable groups. The fact that Blacks and Hispanics are most vulnerable to rising energy prices is not a fact of nature, but a consequence of deliberate political choices about the organisation of US society, just like US expenditure on development aid - as is proven by the different choices made in many European countries. To recruit the domestic poor of the wealthiest nation in the world and the poor of developing countries in defence of non-ratification of the Kyoto Protocol is intellectually suspect, to say the least.

\section{Conclusions}

Today, the United States is as dependent on fossil fuels for its patterns of consumption and production as its South was on slavery in the mid-nineteenth century. It may therefore be unsurprising that US congressmen often rationalise fossil fuel use despite climate risk to 
future generations, just as slavery was rationalised despite ideals of equality. "Errors that slumber peacefully through one age, may be instantly detected in the next, because they are looked at from other points of observation," the ante-bellum orator Tarbox noted in 1843. Of course we must wait for a future timeframe from which to effectively judge today's public discourse on global warming. By recalling the abolition debates, however, we open a new window on the climate debate, one that I hope will shed new light.

A second reason for entertaining a certain amount of suspicion about the present climate debate is the following. In the case of uncertain risk, of which climate change is a textbook example, there is no uniquely and objectively 'right' approach to risk management. Faced with incomplete and often contradictory information, people perceive the world through a cultural filter that affects the way issues are defined and preferences as to how they should be handled (see e.g. Douglas and Wildavsky 1982; Adams 1995). One thing that may justifiably be demanded of any intellectual debate, however, is consistency. One essential element of judging attitudes towards the management of climate risk, therefore, is to compare them with attitudes expressed in other cases. In this article I have argued that this consistency is often lacking in the US congressional debates on the Kyoto Protocol.

In this article I have not argued for or against any particular kind of climate policy. What I hope to have made clear, however, is how the kind of reactionary rhetoric employed in the US congressional debates on the Kyoto Protocol, of which many examples have here been cited, is obstructing the dialogue and deliberation that is so essential for well-considered choices in a matter of such potentially historic importance.

\section{References}

Adams J (1995) Risk. University College London, London

Azar C, Schneider SH (2002) Are the economic costs of stabilising the atmosphere prohibitive? Ecol Econ 42(1-2):73-80

Bush GW (2001) Letter from the President to Senators Hagel, Helms, Craig, and Roberts. http://www. whitehouse.gov/news/releases/2001/03/20010314.html. Cited 13 March 2001

Calhoun JC (1849) The southern address. In: Crallé RK (ed) The works of John C. Calhoun: a disquisition on government and a discourse on the constitution and government of the United States. Charleston, SC, 1851, vol. VI, pp. 290-313

CG, Congressional Globe: record of the congressional debates of the 23rd through 42nd Congresses (1833-73). http://memory.loc.gov/ammem/amlaw/lwcglink.html

CR, Congressional Record http://www.gpoaccess.gov/crecord/retrieve.html

Douglas M, Wildavsky A (1982) Risk and culture: an essay on the selection of technological and environmental dangers. University of California Press, Berkeley, CA

EIA (Energy Information Administration) (1998) Impacts of the Kyoto Protocol on U.S. Energy Markets and Economic Activity, U.S. Department of Energy, Washington, DC. http://www.eia.doe.gov/oiaf/kyoto/ pdf/sroiaf9803.pdf

EIA (Energy Information Administration) (2004) International Energy Outlook 2004, DOE/EIA-0484(2004), Washington, DC

EPA (Environmental Protection Agency) (2003) Memorandum August 28, 2003. http://www.epa.gov/ airlinks/co2petitiongcmemo8-28.pdf

Hansen J (2005) A slippery slope: how much global warming constitutes "dangerous anthropogenic interference"? An editorial essay. Clim Change 68(3):269-279

Hirschman AO (1991) The rhetoric of reaction: perversity, futility, jeopardy. Harvard University Press, Harvard

Hummel JR (1996) Emancipating slaves, enslaving free men: a history of the American civil war. Open Court, Chicago

IPCC (1995) Climate change 1995. Cambridge University Press, Cambridge

IPCC (2001) Climate change 2001. Cambridge University Press, Cambridge

Jenkins WS (1935) Pro-slavery thought in the old south. University of North Carolina Press, Chapel Hill 
Lincoln A (1860) The complete works of Abraham Lincoln. The Tandy - Thomas Co., New York, 1905 , vol. V, pp. 343-44

Meyer A (2000) Contraction \& convergence: the global solution to climate change. Schumacher briefing no. 5. Green Books, Bristol

Miller WL (1996) Arguing about slavery, The great battle in the United States Congress. Knopf, New York

Müller B (2000) Congressional climate change hearings: comedy or tragedy? A primer for aliens. http:// www.wolfson.ox.ac.uk/ mueller/primer.pdf

Müller B (2001) Varieties of distributive justice in climate change. Clim Change 48(2-3):273-288

NAS (1998) Statement by the Council of the National Academy of Sciences regarding Global Change Petition. http://www4.nationalacademies.org/news.nsf/isbn/s04201998?OpenDocument. Cited 20 April 1998

NAS (2001) Climate change science: an analysis of some key questions. National Academy Press, Washington, DC

Orr D (2000) 2020: a proposal. Conserv Biol 14(2):338-341

PEW Center on Global Climate Change (2004) Climate change activities in the U.S.: 2004 Update, Arlington. www.pewclimate.org

RDC, Gales \& Seaton's Register of Debates in Congress: record of the congressional debates of the 18th Congress, 2nd Session through the 25th Congress, 1st Session (1824-37). http://memory.loc.gov/ ammem/amlaw/lwrdlink.html

Robinson AR, Baliunas SL, Soon W, Robinson, ZW (1998) Environmental effects of increased atmospheric carbon dioxide. Oregon Institute of Science and Medicine, http://www.oism.org/pproject/index.htm

Simms WG (1852) The pro-slavery argument; as maintained by the most distinguished writers of the Southern States, containing the several essays on the subject of Chancellor Harper, Governor Hammond, Dr. Simms, and Professor Dew, Charleston, Walker, Richards \& Co. http://www.hti.umich.edu/cgi/t/text/ text-idx?c=moa;idno=ABT7488.0001.001

Tarbox IN (1843) An address on the origin, progress \& present condition of philosophy 4, Utica

Tise LE (1987) Proslavery: a history of the defense of slavery in America. University of Georgia Press, Athens, p1701-1840

US Census (1860) Population of the United States in 1860, pp. 598-599

U.S. Census Bureau (2004) International Population Reports WP/02, Global Population Profile: 2002. US Government Printing Office, Washington, DC

WEFA (Wharton Econometric Forecasting Associates) (1998) Global warming: the high cost of the Kyoto Protocol. Eddystone, PA. See executive summary at http://www.api.org/globalclimate/wefa/exec.pdf. 